\title{
Corrosion Effect of Sweet Cassava Fluid on Steels under Different Working Conditions
}

\author{
*Durowoju, M.O, Babatunde, I.A., Adedoyin, O.J., and Oladosu, K.O. \\ Department of Mechanical Engineering, Ladoke Akintola University of Technology, Ogbomosho
}

\begin{abstract}
One of the most widely used materials in agro-processing fabrication is steel. However, cassava has been found to contain aggressive ions which have deleterious effect on the compositional constituents of steels used in cassava processing industries resulting in an untimely failure in service. This research was carried out to study the corrosion rate of mild steel (with and without surface protection) immersed in a sweet cassava juice media (Oko iyawo) subjected to two different exposure duration; continuous and intermittent. Periodic weight loss measurement and the relationship between weight loss and exposure time were determined. The result obtained shows that galvanized steel had the highest rate of corrosion during the time of exposure compared to painted mild steel, while normal mild steel with no surface protection had the least corrosion rate throughout the immersion period.
\end{abstract}

Keywords: Corrosion Rate, Steels, Immersion Periods and Environmental Conditions

\section{Introduction}

Corrosion is a complex process characterized by a chemical or electrochemical reaction which proceeds in a relatively uniform manner over the entire area of a material or structure (Asafa and Durowoju, 2009; Odidi, 2002). Steel is widely applied in many important devices in petroleum industry, chemical engineering, power generation, nuclear engineering, food processing industries and other engineering fields (Zhang et al., 2005). Under the conditions of highly polluted environment of chloride ions, Zhang et al., (2005) revealed that stress corrosion cracking and serious pitting corrosion often take place in 304 stainless steel. However, corrosion is said to be a destructive phenomenon of which its economic effects is detrimental to the appearance of metals and in some cases can cause equipment failure (Fontana et al., 1987; Daramola et al., 2011). Oluwole et al., (2007) investigated the corrosion resistance of nickel-plated medium carbon steel and 18/8 stainless steel in cassava fluid containing hydrogen cyanide. Jekayinfa et al., (2005) examined the effect of fluid squeezed from cassava tuber on the corrosion behaviour of mild steel. The investigation involves periodic weight loss measurements of $0.8 \%$ carbon and $0.36 \%$ carbon steel rod. The relationship between loss in weight of the exposed samples and exposure period were determined. By employing various corrosion data, numerous experimental and theoretical studies have been carried out to reveal the characteristics and mechanism of these various localized corrosions in steel (Jekayinfa et al., 2005; Bodude et al., 2012). This work therefore examined the corrosion rates of mild steel with surface treatment in a sweet cassava media under different environmental conditions.

\subsection{Specimen Preparation}

\section{Experimental Procedure}

The materials used for the experimental study were mild steel, galvanized steel and painted mild steel with a paint film of $0.1 \mathrm{~mm}$. The elemental composition of the samples was conducted via Minipal 4 Spectrometer, Table 1 . The samples were machined into rectangular sections of $20 \mathrm{~mm}$ by $30 \mathrm{~mm}$ by $1 \mathrm{~mm}$ thickness using cutting machine. The samples were then polished with emery papers of progressively fine grade $220,320,400$ and 600 . The samples were rinsed in distilled water before drying.

\subsection{Preparation of Cassava fluid}

Freshly uprooted sweet cassava tubers (TME-7) popularly known as "Oko iyawo", were obtained from the farm land. The tubers were peeled, grated and squeezed manually using a simple hydraulic press to obtain fresh cassava juice.

Intermittent Condition: On a weekly basis the cassava fluid was replaced with fresh one of the same cassava specie. The steel samples were introduced into the new fluid for a period of 8 weeks.

Continuous Condition: Samples were also left in the solution for the same period of 8 weeks. The $\mathrm{pH}$ for the continuous cassava juice media was checked on a weekly basis to ascertain the variation in hydrogen and hydroxyl ions as a result of biological process of fermentation for the continuous experiment.

The corroded samples were removed and gently cleaned in distilled water before drying. The dried samples were weighed accordingly. 


\subsection{Metallographic Preparation}

Figure 1.5 shows the micrographs of the corroded parts obtained using optical metallurgical microscope XJL-17 model. The specimens were gently clean in a $2 \%$ Sodium hydroxide solution $(\mathrm{NaOH})$ for about $5-10$ seconds to reveal the corroded structure. It was washed, dried and later viewed under the optical microscope.

Table 1a: Elemental Compositional of the Mild Steel

\begin{tabular}{|l|l|l|l|l|l|l|l|l|}
\hline $\mathrm{C}$ & $\mathrm{Si}$ & $\mathrm{Mn}$ & $\mathrm{P}$ & $\mathrm{Cu}$ & $\mathrm{S}$ & $\mathrm{Cr}$ & $\mathrm{Ni}$ & $\mathrm{Mo}$ \\
\hline 0.112 & $<0.0001$ & 0.313 & 0.011 & 0.428 & 0.018 & 0.013 & 0.029 & $<0.0001$ \\
\hline $\mathrm{Ti}$ & $\mathrm{Nb}$ & $\mathrm{V}$ & $\mathrm{Co}$ & $\mathrm{W}$ & $\mathrm{Bi}$ & $\mathrm{Pb}$ & $\mathrm{B}$ & $\mathrm{Sn}$ \\
\hline 0.0007 & 0.0072 & 0.003 & 0.022 & $<0.0001$ & 0.0009 & 0.008 & 0.004 & 0.0013 \\
\hline $\mathrm{Ca}$ & $\mathrm{Ce}$ & $\mathrm{Zi}$ & $\mathrm{Zr}$ & $\mathrm{La}$ & $\mathrm{Al}$ & $\mathrm{As}$ & $\mathrm{Zn}$ & $\mathrm{Fe}$ \\
\hline 0.0002 & 0.0064 & 0.0032 & - & 0.0005 & 0.00064 & $<0.0001$ & 0.005 & 99.4 \\
\hline
\end{tabular}

Table 1b: Elemental Compositional of the Galvanized Steel

\begin{tabular}{|l|l|l|l|l|l|l|l|l|}
\hline $\mathrm{C}$ & $\mathrm{Si}$ & $\mathrm{Mn}$ & $\mathrm{P}$ & $\mathrm{S}$ & $\mathrm{Cr}$ & $\mathrm{Ni}$ & $\mathrm{Mo}$ & $\mathrm{Al}$ \\
\hline 0.074 & $<0.0001$ & 0.207 & 0.0020 & 0.0033 & 0.0024 & 0.017 & $<0.0001$ & 0.033 \\
\hline $\mathrm{Ti}$ & $\mathrm{Nb}$ & $\mathrm{V}$ & $\mathrm{W}$ & $\mathrm{Pb}$ & $\mathrm{B}$ & $\mathrm{Sn}$ & $\mathrm{Zn}$ \\
\hline 0.0007 & 0.0064 & 0.0026 & $<0.0001$ & 0.0056 & 0.004 & 0.0009 & 0.005 & $\mathrm{As}$ \\
\hline $\mathrm{Zi}$ & $\mathrm{Zr}$ & $\mathrm{La}$ & $\mathrm{Co}$ & $\mathrm{Ce}$ & $\mathrm{Cu}$ & $\mathrm{Ca}$ & $\mathrm{Bi}$ & $\mathrm{Fe}$ \\
\hline- & 0.0064 & 0.0009 & 0.0021 & 0.006 & 0.006 & 0.0002 & 0.001 & 99.6 \\
\hline
\end{tabular}

\section{Result and Discussion}

Table 2.1 shows the corrosion rate of samples exposed to sweet cassava fluid without atmospheric interaction for continuous time frame. For the three steels considered, there was an increase in the corrosion rate with time up to around 8 to 12 days. After this, further exposure caused a sharp decrease in the corrosion rate which is more pronounced in galvanized steel, as depicted in Figure 1.1. After 30 days, the corrosion rate tends to be stable for galvanized steel. For painted steel, there was a slight increase in the corrosion rate between 13- 21 days. Further exposure resulted in a constant value of 0.36 . Similar behaviour was observed in normal steel between $13-21$ days. Further exposure above 21 days caused a gradual increase in corrosion rate. This can be attributed to the low percentage of carbon and other micro alloying elements such as $\mathrm{P}, \mathrm{Cu}, \mathrm{S}$ and $\mathrm{Cr}$ present in galvanized steel.

Table 2.1: Corrosion Rate of samples in Sweet Continuous Media without Atmospheric Interaction

\begin{tabular}{|c|c|c|c|c|c|c|c|c|c|c|}
\hline \multirow[b]{2}{*}{$\begin{array}{l}\text { Exposu } \\
\text { re time } \\
\text { (days) }\end{array}$} & \multicolumn{3}{|c|}{ Galvanized Steel } & \multicolumn{3}{|c|}{ Painted Steel } & \multicolumn{4}{|c|}{ Normal Steel } \\
\hline & $\begin{array}{l}\text { Weight of } \\
\text { Sample (g) }\end{array}$ & $\begin{array}{l}\text { Weight } \\
\text { loss (g) }\end{array}$ & Rate & $\begin{array}{l}\text { Weight of } \\
\text { Sample (g) }\end{array}$ & $\begin{array}{l}\text { Weight } \\
\text { loss (g) }\end{array}$ & Rate & $\begin{array}{l}\text { Weight of } \\
\text { Sample (g) }\end{array}$ & $\begin{array}{l}\text { Weight } \\
\text { loss }(\mathrm{g})\end{array}$ & Rate & $\mathrm{pH}$ \\
\hline 0 & 4.29 & 0.00 & 0.00 & 3.87 & 0.00 & 0.00 & 3.43 & 0.00 & 0.00 & 6.0 \\
\hline 7 & 4.19 & 0.10 & 1.10 & 3.83 & 0.04 & 0.44 & 3.41 & 0.02 & 0.22 & 3.9 \\
\hline 14 & 4.17 & 0.12 & 1.66 & 3.81 & 0.06 & 0.33 & 3.41 & 0.02 & 0.11 & 2.9 \\
\hline 21 & 4.14 & 0.15 & 0.55 & 3.77 & 0.10 & 0.36 & 3.38 & 0.05 & 0.18 & 2.6 \\
\hline 28 & 4.13 & 0.16 & 0.44 & 3.74 & 0.13 & 0.35 & 3.36 & 0.07 & 0.19 & 2.5 \\
\hline 35 & 4.11 & 0.18 & 0.39 & 3.72 & 0.15 & 0.33 & 3.34 & 0.09 & 0.19 & 2.3 \\
\hline 42 & 4.08 & 0.21 & 0.38 & 3.70 & 0.17 & 0.31 & 3.30 & 0.13 & 0.23 & 2.0 \\
\hline 49 & 4.06 & 0.23 & 0.36 & 3.68 & 0.19 & 0.30 & 3.27 & 0.16 & 0.25 & 2.0 \\
\hline 56 & 4.03 & 0.26 & 0.35 & 3.65 & 0.22 & 0.30 & 3.23 & 0.20 & 0.27 & 2.0 \\
\hline
\end{tabular}

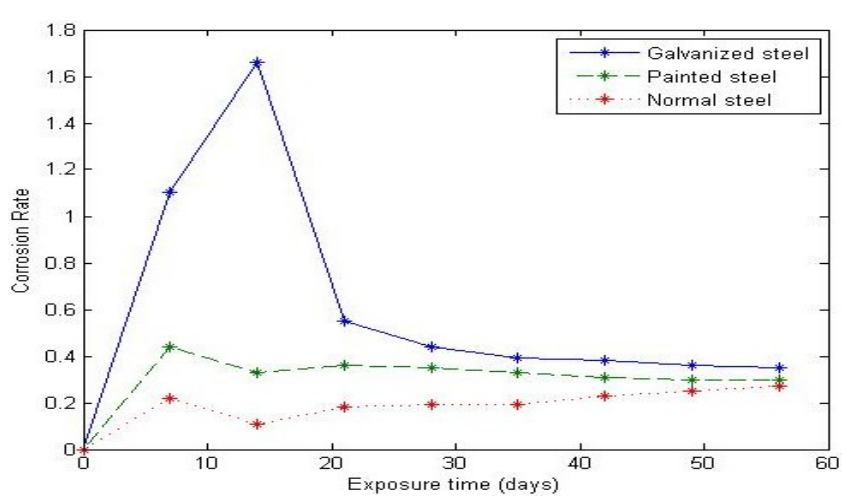

Figure 1.1: Graph of Corrosion rate against Exposure time for sweet Continuous Media Without Atmospheric Interaction 
The corrosion rate of samples exposed to sweet cassava fluid media without atmospheric interaction during an intermittent exposure time was shown in Table 2.2 and Figure 1.2 respectively.

From Figure 1.2, it was observed that the corrosion rate of galvanized steel increases up to 1.55 for the first 8 days of exposure and continuously reduces over the entire period. In painted mild steel, there is an increase in corrosion rate up to 0.47 for first period of 8 days of exposure over which further exposure caused decrease in corrosion rate which remain constant between $28-56$ days of exposure. The normal mild steel on the other hand, increases steadily during the exposure time. Though, the rate of corrosion is no longer significant after 40 days of exposure.

However, the corrosion rate of sample exposed to sweet cassava fluid media with atmospheric interaction during continuous time of exposure was shown in Table 2.3 and Figure 1.3 respectively.

At the initial stage of the experiment it was obvious from Figure 1.3, that galvanized steel samples had high rate of corrosion which increases for the up to 14 days of exposure compared with painted or normal mild steel. It is evidence that with the presence of atmospheric interaction, rate of corrosion of galvanized steel in cassava fluid media is more pronounced when compared with samples not exposed to atmosphere. At the same time, the rate of decrease in corrosion rate is not significant unlike the samples without atmosphere (Figure 1.1) where the rate of corrosion decreases rapidly. However, similar behaviour was observed for the corrosion rate of painted mild steel samples in the same medium with or without atmospheric condition while normal mild steel exhibit little corrosion rate over the exposure time.

Similarly, the corrosion rate of samples exposed to sweet cassava fluid media with atmospheric interaction during an intermittent exposure period were shown in Table 2.4 and Figure 1.4.

From Figure 1.4, the rate of corrosion in both galvanized steel and painted mild steel increases up to the first 8 days of exposure. Further exposure caused decrease in corrosion rate of both specimens. This may be attributed to the aggressiveness of the chemical re-activities, transport properties of environment, concentration of corrosive fluid $(\mathrm{pH})$ and temperature of the corrosive medium. In addition, the rate of corrosion in normal mild steel also increases for the first 8 days of exposure when compared with sample not exposed to atmospheric condition (Figure 1.2), which becomes almost stable overtime.

Table 2.2: Corrosion Rate of samples in Sweet Intermittent media Without Atmospheric Interaction

\begin{tabular}{|c|c|c|c|c|c|c|c|c|c|}
\hline \multicolumn{4}{|c|}{ Galvanized Steel } & \multicolumn{3}{|c|}{ Painted Steel } & \multicolumn{3}{|c|}{ Normal Steel } \\
\hline $\begin{array}{l}\text { Exposure } \\
\text { time } \\
\text { (days) }\end{array}$ & $\begin{array}{l}\text { Weight of } \\
\text { Sample } \\
\text { (g) }\end{array}$ & $\begin{array}{l}\text { Weight } \\
\text { loss (g) }\end{array}$ & Rate & $\begin{array}{l}\text { Weight of } \\
\text { Sample (g) }\end{array}$ & $\begin{array}{l}\text { Weight } \\
\text { loss (g) }\end{array}$ & Rate & $\begin{array}{l}\text { Weight of } \\
\text { Sample } \\
\text { (g) }\end{array}$ & $\begin{array}{l}\text { Weight } \\
\operatorname{loss}(g)\end{array}$ & Rate \\
\hline 0 & 4.12 & 0.00 & 0.00 & 5.04 & 0.00 & 0.00 & 3.21 & 0.00 & 0.00 \\
\hline 7 & 3.98 & 0.14 & 1.54 & 5.00 & 0.04 & 0.44 & 3.21 & 0.00 & 0.00 \\
\hline 14 & 3.91 & 0.21 & 1.16 & 4.98 & 0.06 & 0.33 & 3.20 & 0.01 & 0.05 \\
\hline 21 & 3.89 & 0.23 & 0.84 & 4.96 & 0.08 & 0.29 & 3.19 & 0.02 & 0.07 \\
\hline 28 & 3.85 & 0.27 & 0.74 & 4.95 & 0.09 & 0.24 & 3.18 & 0.03 & 0.08 \\
\hline 35 & 3.82 & 0.30 & 0.66 & 4.92 & 0.12 & 0.26 & 3.17 & 0.04 & 0.08 \\
\hline 42 & 3.80 & 0.32 & 0.58 & 4.90 & 0.14 & 0.25 & 3.15 & 0.06 & 0.11 \\
\hline 49 & 3.78 & 0.34 & 0.53 & 4.87 & 0.17 & 0.26 & 3.13 & 0.08 & 0.12 \\
\hline 56 & 3.75 & 0.37 & 0.51 & 4.85 & 0.19 & 0.26 & 3.12 & 0.09 & 0.12 \\
\hline
\end{tabular}

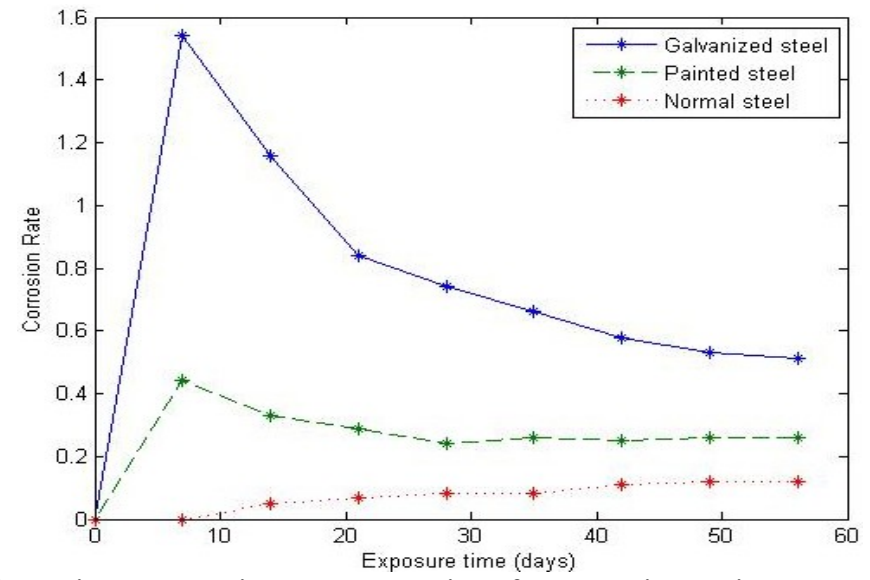

Figure 1.2: Graph of Corrosion rate against Exposure time for sweet intermittent Media without Atmospheric Interaction 
Corrosion Effect of Sweet Cassava Fluid on Steels under Different Working Conditions

Table 2.3: Corrosion Rate of samples in Sweet Continuous Media With Atmospheric Interaction

\begin{tabular}{|c|c|c|c|c|c|c|c|c|c|c|}
\hline \multirow[b]{2}{*}{$\begin{array}{l}\text { Exposure } \\
\text { time (days) }\end{array}$} & \multicolumn{3}{|c|}{ Galvanized Steel } & \multicolumn{3}{|l|}{ Painted Steel } & \multicolumn{2}{|c|}{ Normal Steel } & \multirow[b]{2}{*}{ Rate } & \multirow[b]{2}{*}{$\mathrm{pH}$} \\
\hline & $\begin{array}{l}\text { Weight of } \\
\text { Sample (g) }\end{array}$ & $\begin{array}{l}\text { Weight } \\
\text { loss (g) }\end{array}$ & Rate & $\begin{array}{l}\text { Weight of } \\
\text { Sample (g) }\end{array}$ & $\begin{array}{l}\text { Weight } \\
\text { loss (g) }\end{array}$ & Rate & $\begin{array}{l}\text { Weight of } \\
\text { Sample (g) }\end{array}$ & $\begin{array}{l}\text { Weight } \\
\operatorname{loss}(\mathrm{g})\end{array}$ & & \\
\hline 0 & 4.44 & 0.00 & 0.00 & 4.21 & 0.00 & 0.00 & 3.15 & 0.00 & 0.00 & 6.0 \\
\hline 7 & 4.28 & 0.16 & 1.76 & 4.16 & 0.05 & 0.55 & 3.15 & 0.00 & 0.00 & 3.9 \\
\hline 14 & 4.03 & 0.41 & 2.26 & 4.15 & 0.06 & 0.33 & 3.14 & 0.01 & 0.05 & 2.6 \\
\hline 21 & 4.01 & 0.43 & 1.58 & 4.14 & 0.07 & 0.25 & 3.14 & 0.01 & 0.03 & 2.5 \\
\hline 28 & 3.98 & 0.46 & 1.27 & 4.13 & 0.08 & 0.22 & 3.13 & 0.02 & 0.05 & 2.3 \\
\hline 35 & 3.95 & 0.49 & 1.08 & 4.12 & 0.09 & 0.19 & 3.12 & 0.03 & 0.06 & 2.0 \\
\hline 42 & 3.91 & 0.53 & 0.97 & 4.11 & 0.10 & 0.18 & 3.11 & 0.04 & 0.07 & 2.0 \\
\hline 49 & 3.87 & 0.57 & 0.90 & 4.10 & 0.11 & 0.17 & 3.09 & 0.06 & 0.09 & 2.0 \\
\hline 56 & 3.83 & 0.61 & 0.84 & 4.07 & 0.14 & 0.19 & 3.07 & 0.08 & 0.11 & 2.0 \\
\hline
\end{tabular}

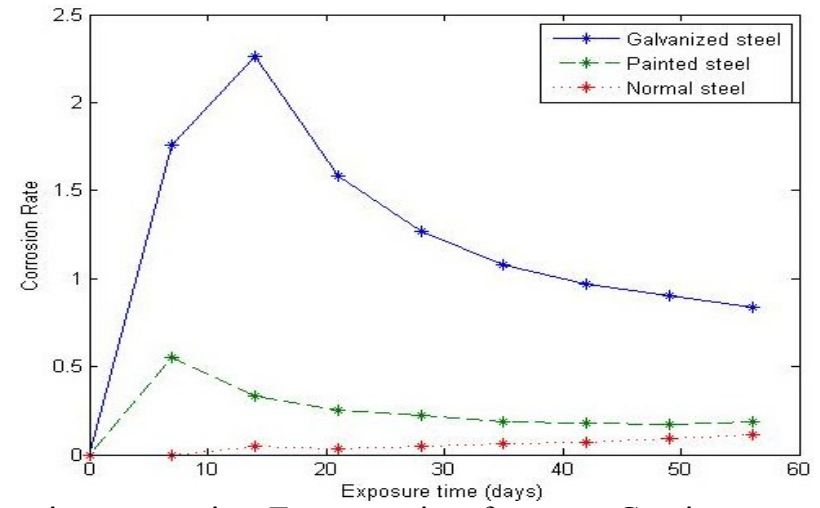

Figure 1.3: Graph of Corrosion rate against Exposure time for sweet Continuous media Without Atmospheric Interaction

Table 2.4: Corrosion rate of samples in Sweet Intermittent media With Atmospheric Interaction

\begin{tabular}{|c|c|c|c|c|c|c|c|c|c|}
\hline \multicolumn{4}{|c|}{ GalvanizedSteel } & \multicolumn{3}{|c|}{ Painted Steel } & \multicolumn{3}{|c|}{ Normal Steel } \\
\hline $\begin{array}{l}\text { Exposure } \\
\text { time (days) }\end{array}$ & $\begin{array}{l}\text { Weight of } \\
\text { Sample (g) }\end{array}$ & $\begin{array}{l}\text { Weight } \\
\text { loss (g) }\end{array}$ & Rate & $\begin{array}{l}\text { Weight of } \\
\text { Sample (g) }\end{array}$ & $\begin{array}{l}\text { Weight } \\
\text { loss (g) }\end{array}$ & Rate & $\begin{array}{l}\text { Weight of } \\
\text { Sample (g) }\end{array}$ & $\begin{array}{l}\text { Weight } \\
\text { loss(g) }\end{array}$ & Rate \\
\hline 0 & 4.07 & 0.00 & 0.00 & 3.49 & 0.00 & 0.00 & 4.86 & 0.00 & 0.00 \\
\hline 7 & 3.94 & 0.13 & 1.43 & 3.49 & 0.00 & 0.00 & 4.86 & 0.00 & 0.00 \\
\hline 14 & 3.93 & 0.14 & 0.77 & 3.47 & 0.02 & 0.11 & 4.84 & 0.02 & 0.11 \\
\hline 21 & 3.90 & 0.17 & 0.62 & 3.40 & 0.09 & 0.33 & 4.81 & 0.05 & 0.18 \\
\hline 28 & 3.88 & 0.19 & 0.52 & 3.38 & 0.11 & 0.30 & 4.79 & 0.07 & 0.19 \\
\hline 35 & 3.87 & 0.20 & 0.44 & 3.34 & 0.15 & 0.33 & 4.77 & 0.09 & 0.19 \\
\hline 42 & 3.86 & 0.21 & 0.38 & 3.31 & 0.18 & 0.33 & 4.74 & 0.12 & 0.20 \\
\hline 49 & 3.85 & 0.22 & 0.34 & 3.29 & 0.20 & 0.31 & 4.74 & 0.12 & 0.18 \\
\hline 56 & 3.82 & 0.25 & 0.34 & 3.27 & 0.22 & 0.30 & 4.72 & 0.14 & 0.19 \\
\hline
\end{tabular}

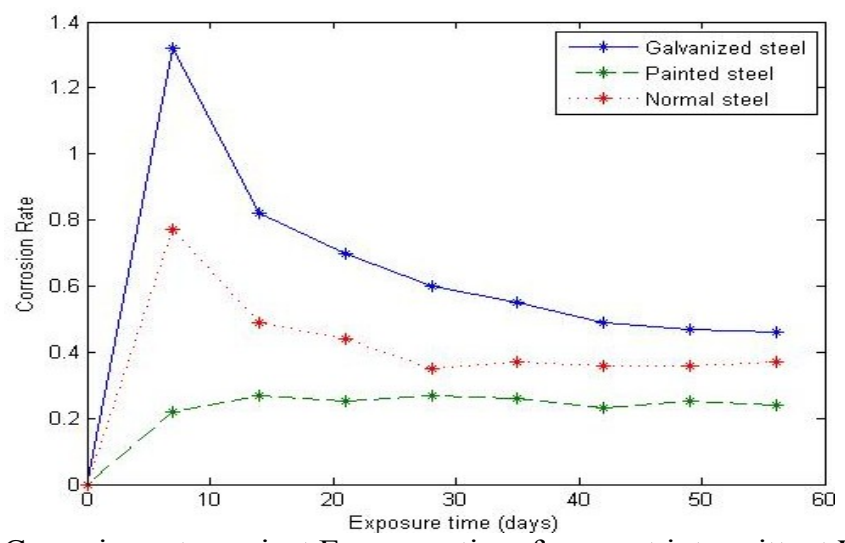

Figure 1.4: Graph of Corrosion rate against Exposure time for sweet intermittent Without Atmospheric Interaction 


\section{Metallographic Observation}

Figure 1.5 revealed the various degree of corrosion that took place in each of the sample over a period of 54 days of exposure. It was observed that galvanized steel had highest level of corrosion compared with painted and normal steel as shown in the Figures above.

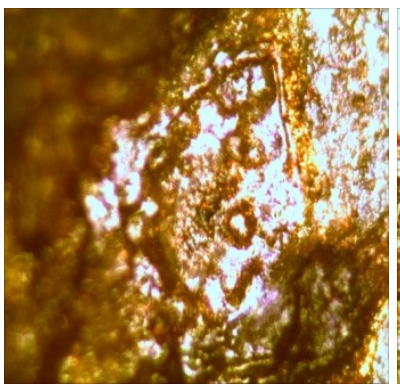

GSAC

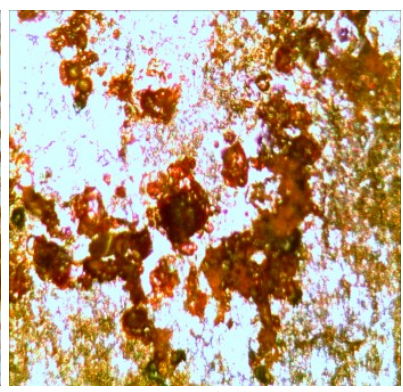

GSWAC

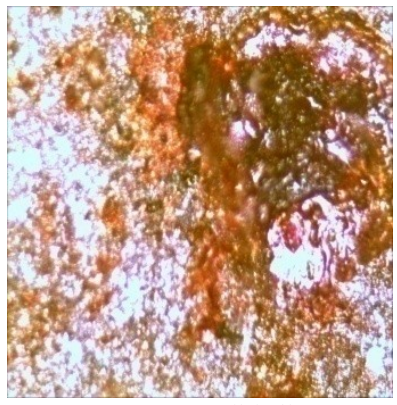

PSAC

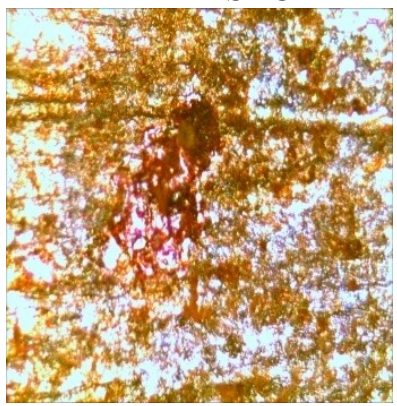

NMSAC

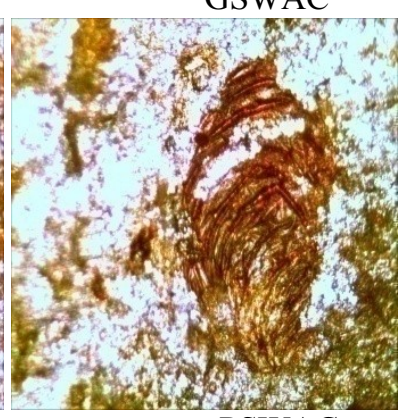

PSWAC

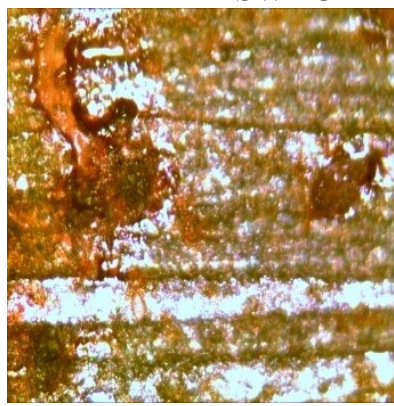

NMSWAC

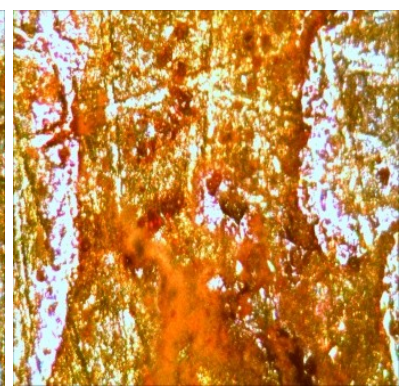

GSAI

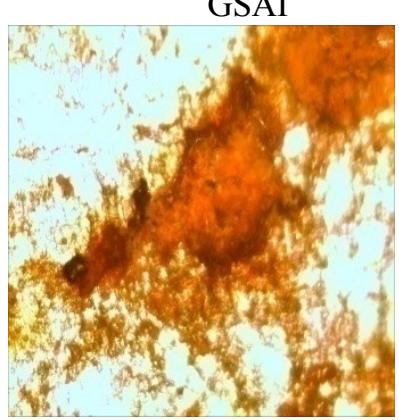

PSAI

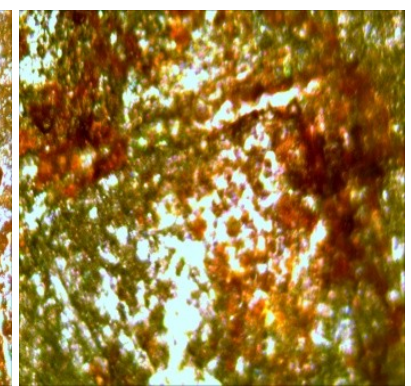

GSWAI

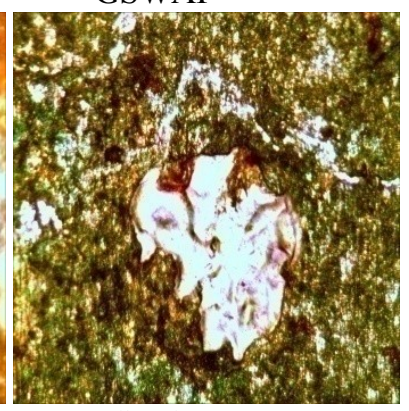

PSWAI

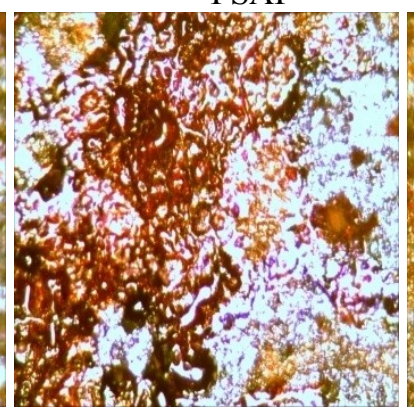

NMSAI

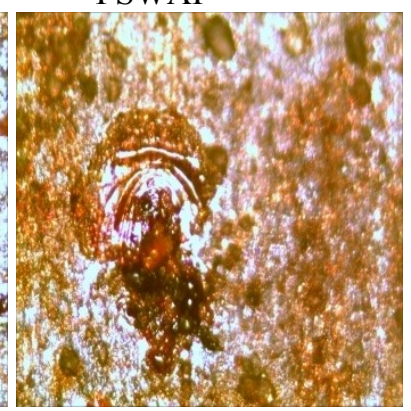

NMSWAI

Figure 1.5: $\quad$ Microstructures of the Corroded Galvanized Steel, Painted and Normal Mild Steel

\section{Conclusion}

From this study, galvanized steel samples showed an aggressive rate of corrosion in cassava fluid media in both continuous and intermittent conditions, and with or without atmospheric interaction. Painted mild steel exhibited similar phenomenon during the experimental study but the rate of corrosion was less pronounced. Normal mild steel samples however, revealed low rate of corrosion in both continuous and intermittent conditions, and with or without atmospheric interaction. Thus, normal mild steel can be a preferred choice for cassava processing equipment in both continuous and intermittent conditions, and with or without atmospheric interaction. This will eventually reduce the cost of damage and replacements of machinery part during maintenance operation.

NB: GS: Galvanized steel; PS: Painted mild steel; NMS: Normal mild steel AC: atmospheric continuous process, WAC: Without atmospheric continuous process, AI: atmospheric intermittent process, WAI: Without atmospheric intermittent process

\section{References}

[1]. Asafa, T.B. and Durowoju, M.O. (2009), "Assessment of a Nigeria mild steel under some selected corrosion environments", Science Focus, Vol. 14, No. 2, Pp. $136-145$

[2]. Adebiyi, K.A., Hammed, K.A. and Ajayi, E.O. (2003), "Predictive model for evaluating corrosion rate of mild steel in six environments", LAUTECH Journal of Engineering and Technology.

[3]. Bodude, M. A., Ayoola, W.A., Esezobor, D. E. and Agbeleye, A. A. (2012), "Corrosion-Wear of ST60-Mn Steel in Cassava Juice", Journal of Minerals \& Materials Characterization \& Engineering, Vol. 11, No.2, Pp. $153-158$.

[4]. Daramola, O.O., Adewuyi, B.O. and Oladele, I.O. (2011), "Corrosion Behaviour of Heat Treated Rolled Medium Carbon Steel in Marine Environment”, Journal of Minerals \& Materials Characterization \& Engineering, Vol. 10, No.10, Pp. 888 - 903. 
[5]. Fontana, M.G. (1986), Corrosion Engineering, 3rd Edition, McGraw Hill Book Company, U.S.A.

[6]. Jekayinfa, S.O., Waheed, M.A., Adebiyi, K.A. and Adebiyi, F.T. (2005), "Effect of Cassava Fluid on Corrosion Performance of Mild Steel", Anti- Corrosion methods and materials, Vol. 52, No. 5, Pp. $286-292$.

[7]. Oluwole, O.O., Atanda, P.O., Odekunbi, O.A. and Odegbaju, E. (2009), "Corrosion Behavior of 18/8 Stainless Steel and NickelPlated Low Carbon Steel in Cassava Fluid", Journal of Minerals \& Materials Characterization \& Engineering, Vol. 8, No.10, Pp. $803-811$.

[8]. Odidi, J.J. (2002), "The Effects of Surface Finish on the Corrosion Rate of Steel”, Nigerian Journal of Engineering Research and Development, Vol. 1, Pp. 1 - 9.

[9]. Zhang, W., Liang, C. and Gao, Z. (2005), "Electrochemical test of 304 stainless steel and fractal characteristic of pits distribution”, Journal of Pressure Equipment and Systems, Vol. 3, Pp. 149 - 152. 